\section{Three Approaches to the Study of Personality*}

\section{ALASTAIR HERON}

\section{From the Medical Research Council Unit for Research in Occupational Adaptation}

Human personality has since time immemorial provided an attractive subject for philosophers and writers, but only very recently has it come within the purview of students committed to use scientific methods of enquiry. Not unexpectedly, these pioneers found their material less amenable to controlled investigation than had been the case with that studied by physicists and chemists, anatomists and physiologists. Two other difficulties soon became evident, however. Of these, one was the simple fact that the relationship between the student and the object of study was of so unique a kind as to demand some totally new departures in method; the other, the consequences for generalization implied by almost limitless variations among the individual units concerned. To such formidable obstacles there were many possible patterns of response ; many readers will have made up their minds long ago to stick to Shakespeare and they are not advised to attempt the digestion of any of these three books. Their appeal can only be to those who still believe strongly that human personality should be, at least to some extent, susceptible of objective description, classification and assessment, and that in spite of inherent limitations, human behaviour should be partially predictable.

Of the three volumes, that by the late Bernard Notcutt, Professor of Psychology in the University of Natal, is without doubt the easiest to read. He described his book as " an attempt to choose, from among the great variety of current psychological concepts and methods, those that have the best promise for the future", and its purpose as "more to evaluate than to describe the activities of psychologists". His choice and his evaluations were evidently and understandably affected by his own preference for a combination of what have been called the holistic and longitudinal approaches to the study of personality. Dr. Eysenck, Reader in Psychology at the Institute of Psychiatry, University of London, did not set out to choose and to evaluate, but in his latest book continues to affirm with characteristic vigour his adherence to the atomistic and cross-sectional approaches. This is not, however, solely or perhaps even mainly a matter of preference, for he adduces evidence to show that, for prediction purposes at least, these non-global methods are so far superior.

The time has certainly come when it is no longer possible to assume that every educated reader or listener

\footnotetext{
*The Psychology of Personality. By Bernard Notcutt. (Pp. 259. 21s.) London : Methuen \& Co. Ltd. 1953.

The Structure of Human'Personality. By H. J. Eysenck. (Pp. xiii + 344. 37s. 6d.) London : Methuen \& Co. Ltd. 1953. Personality Tests and Assessments. By Philip E. Vernon. (Pp. xi +
206; illustrated. 18s.) London: Methuen \& Co. L.td. 1953.
}

will interpret the term "scientific" in the same way. For this reason it is essential to say what it meant to Notcutt and Eysenck as students of the psychology of personality. The former (p. 3) stresses three aspects of the scientific method as particularly important for this purpose. There are (1) the formulation of exact, testable hypotheses ; (2) the need for publicly available methods and results which can be repeated by any competent observer; and (3) freedom from moral and aesthetic qualms about what is worth studying and reporting. He lists as secondary desiderata such features as quantification, controlled experimentation, and the development of systematic classification and general principles. Eysenck (flysheet) quotes J. S. Mill as his mentor for an attempt to draw a measure of agreement out of a large number of studies by many investigators, and for claiming that, because factor analysis is the means by which such agreement is possible, it should be adapted for use with the topics where little or no agreement can be found. He therefore places his emphases on all of those features (primary and secondary) listed by Notcutt, but clearly regards them as but means to a single end, that of classification and the statement of general principles. Notcutt is interested mainly in persons as going concerns, and is only secondarily interested in the advancement of a science of persons : Eysenck is primarily a scientist, and studies personality as a natural phenomenon. Both recognize (Notcutt explicitly, pp. 13-14) the divergence of aim and its parallel in medicine in the differing emphasis of clinician and scientist. For reasons themselves largely psychological it is difficult today to find a "clinical scientist" in either medicine or psychology, and but little easier to achieve a genuine mutual respect as a working basis.

This personal difference is well reflected in the general approach of the two authors. Notcutt is warmer, more " humane", and tempted to generalize without providing adequate evidence; Eysenck rather more detached, decidedly impersonal, and abounding with facts and figures. A few samples will suffice to bring this out. On p. 165 Notcutt says flatly, and without supporting evidence, " a self-rating scale is not even the roughest approximation to a true picture of the person ". By contrast, Eysenck devotes two pages, at the end of a 30-page chapter on questionnaires and inventories (which bristles with factual data and references), to a balanced consideration of their inherent weaknesses under various conditions. Similarly, Notcutt is so untroubled by the restrictions of scientific method that on p. 171 he is able to state unabashedly that "the most fruitful use of projective analysis is the interpretation of attitudes" (reviewer's italics). However true this may be for the clinician seeking " leads" in dealing with the single case, it is just the sort of subjective feature which causes psychology to present so contradictory a picture of personality. This is not the same as saying that there are no contradictory elements in personality; to the scientist, the challenge is to accommodate the contradictions in a lawful manner. Characteristically, Eysenck's approach to the type of test incorrectly called " projective", exemplified by the Rorschach and by the 
Thematic Apperception Test, is to quote the results obtained by methods which avoid the very interpretation which Notcutt values so highly, and to integrate the findings with those obtained by other methods.

This is perhaps the appropriate point at which to mention the third volume in this Methuen trilogy which Professor C. A. Mace has edited. It is by Professor P. E. Vernon, of the Institute of Education, University of London, and is best described as a brilliantly annotated guide to the present possibilities of personality assessment. Those readers who are familiar with the pink-covered reports of the Industrial Health Research Board (alas, discontinued since 1947) may have read Vernon's 1938 report on "The Assessment of Psychological Qualities by Verbal Methods", to which the present volume is in some ways a successor. He assumes from the start (p. 4) that readers will know how to evaluate a validity or reliability expressed as a correlation coefficient, or that they are prepared to find out. To the present writer, this seems less unreasonable than might appear ; if a non-specialist wants to use the work of the specialist, then there are minimum requirements to be met. So far as psychological tests are concerned, it means correlation coefficients, variance estimates, and levels of significance. Readers will be grateful for his definition: "A psychological test, by presenting a standardized task or situation, elicits a sample of the testee's behaviour which can be objectively scored and compared with norms of performance, and which has been proved to be predictive of future occupational or other behaviour" (p. 31), and for the frankness of his next sentence : "In the field of personality this is an ideal rather than an actuality ". Here Eysenck is inclined to be a little more confident, for he quotes data to support a claim that the main "dimensions" can be measured with validities but little lower than those regarded as satisfactory for intelligence tests. However, the results are not unequivocal, and obtained from rather atypical groups such as hospital patients and staff and soldiers. In the industrial experience of the writer, such objectively scored tests of personality have proved useful.

Professor Vernon has a good deal to say about the use of the interview for assessing personality which could with profit be read by medical men, both in and out of industry. While recognizing its usefulness (when designed very carefully for a specific purpose) as one of a number of approaches, he makes it clear (as does Eysenck in a chapter on ratings) that its principal characteristics are unreliability and doubtful validity. This he attributes to the scope it gives the interviewer "to jump to false conclusions, and to be influenced by prejudices and unsound theories". In this connexion he quotes (p. 28) from an important American study in which it was found that the degree of confidence felt by the judges in any method (involving personal contact, but excluding objective tests) provided completely misleading indications of its true value! This may not be irrelevant when attempting to evaluate Notcutt's enthusiasm (pp. 157,
188 et seq.) for the "achievements" of the War Office Selection Boards and the equivalent American procedures. The objective evaluations of validity for these methods are more sober, and it is likely that Notcutt's judgement was too much affected by his dislike of tests as atomistic, in contrast with the holism of the Gestalt school to which he adhered. Vernon is more balanced in his view than either Notcutt or Eysenck on this issue.

Quite apart from the merits and demerits of the books themselves, in what way does their appearance add to our knowledge of human personality? Is the confidence of the intelligent, educated and enquiring non-psychologist likely to be enhanced or shaken as he considers our achievements to date? And are the prospects good for fresh advance? To these questions some answer must be essayed, but before doing so one point must be made clear if writer and reader are not to be at cross-purposes. The point in question can be simply stated : the answers to these questions will depend for their meaning and value upon whether or not they imply a belief in the desirability and feasibility of studying personality by rigorous scientific means. If the reader does not accept that implication, then it is likely if not indeed certain that he will reject the answers and not trouble to read any of the books. If he does not accept it, but shares the "holistic and longitudinal" views of Notcutt, he will probably ignore the given answers but read the three books in the order Notcutt, Vernon, Eysenck; the chances of his finishing the last are probably slim ! From this incomplete coverage of the possible responses it will be evident that the writer himself accepts the implication, and his answers should be evaluated accordingly. To the first question, In what way does the appearance of these three books add to our knowledge of human personality? the answer is affirmative. Eysenck and Vernon bring together in manageable compass a previously ill-assorted and apparently incoherent mass of data, showing in the process that some intelligible pattern is emerging. Notcutt, approaching from almost the opposite direction by different means of transport, hastens to clothe the framework which they have so indecently exposed, lamenting the while that it is inhuman and lifeless. To the second question, How is the confidence of the layman likely to be affected ? the answer is probably "Not at all", because facts do not carry much weight where self-acknowledged experts are involved ; but to this there can be exceptions if the non-psychologists are truly enquiring and very persevering. Finally, are the prospects good for fresh advance? They are in some ways better than they were, but we are desperately short of first-class minds, committed to the rigorous demands of the scientific method while capable of formulating new hypotheses which are testable. The psychoanalytic and the Gestalt schools were rich in hypotheses and weak in scientific method, the factoranalysts and test-oriented investigators are on surer methodological foundations, freer from temptation to generalize, but in danger of sterility. 